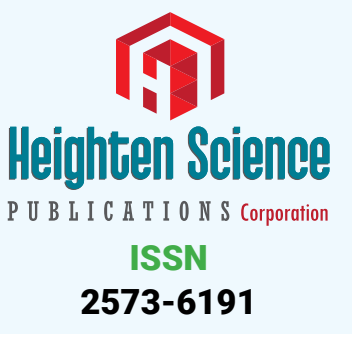

*Address for Correspondence: Siriporn Hirunpat Department of Radiology, Prince of Songkla University, Hat-Yai, Songkhla, Thailand, Tel: 66818976907; Fax: 667442992; Email: hirsirip@ hotmail.com

Submitted: 17 February 2017

Approved: 17 March 2017

Published: 20 March 2017

Copyright: @ 2017 Hirunpat, et al. This is an open access article distributed under the Creative Commons Attribution License, which permits unrestricted use, distribution, and reproduction in any medium, provided the original work is properly cited.

\title{
Normal Value of Skull Base Angle Using the Modified Magnetic Resonance Imaging Technique in Thai Population
}

\author{
Siriporn Hirunpat*, Nat Wimolsiri and Nuttha Sanghan \\ Department of Radiology, Prince of Songkla University, Hat-Yai, Songkhla, Thailand
}

\section{ABSTRACT}

Purpose: To determine the normal value of basal angle measured using the modified MR imaging technique in Thai population compared with the standard value obtained from the Western population.

Materials and Methods: We retrospectively evaluated midline sagittal SE T1 weighted MR images in 200 adults and 50 children. The basal angle of the skull base was measured using the modified MR imaging technique described by Koenigsberg et al. The angle was formed by a line extending across the anterior cranial fossa to the tip of the dorsum sellae and another line drawn along the posterior margin of the clivus. The mean values of the basal angles among different age groups and sex were calculated and analyzed.

Results: The mean skull base angle of our adult population was $115^{\circ}$ (range $100.5^{\circ}-130^{\circ}, \mathrm{SD}=5.7$ ) with an inter-observer agreement of 0.85 , slightly smaller than the previous study from the USA which was $117^{\circ}$. There was no significant difference between the male and female groups. The mean skull base angle in our children population was $114.7^{\circ}$ (range $102-130.5^{\circ}, S D=6.3$ ) with an inter-observer agreement of 0.89 , quite similar to the previous USA study which was $114^{\circ}$. There was no significant difference between adult and children.

Conclusions: The mean adult skull base angle measured using the modified MR imaging technique in Thai population was slightly smaller than the Western population, while the mean skull base angle of children was quite similar. The basal angle range of $103.6^{\circ}-126.4^{\circ}$ may be used as a guide for the potential range of normal skull base angles in Thai population and possibly also the Southeast Asian population.

\section{ABBREVIATIONS}

MRI = Magnetic Resonance Imaging, SE= Spin Echo

\section{INTRODUCTION}

Platybasia is refers to flattening of the skull base, manifested by the increase in skull base angle. Several different techniques have been originally used in plain skull radiography such as the standard measurement using the angle formed between a line drawn from the nasion to the center of the sellar turcica, and a line drawn from the center of the sellar turcica down along the posterior aspect of the clivus. The normal values are slightly different between studies. Most literatures reported that the normal adult basal angle is between $125^{\circ}-143^{\circ}$ and the diagnosis of platybasia is suggested when the angle is more than $143^{\circ}$ [1]. However, some authors recommended a slightly wider range of normal basal angle between $120^{\circ}-150^{\circ}$, with an angle larger than $150^{\circ}$ indicating platybasia [2].

Since MR imaging has supplanted plain skull films in routine head evaluation, 
Koenigsberg et al. [1], suggested the more convenient and reproducible modified MR imaging method of using the angle formed by a line extending across the anterior cranial fossa to the tip of the dorsum sellae, and a line drawn along the posterior margin of the clivus. This measurement yielded a normal value of basal angle range between $100^{\circ}-127^{\circ}$ with a mean of $117^{\circ}(\mathrm{SD}=6)$ and $95 \%$ confidence interval between $116^{\circ}-118^{\circ}$ for adults and $103^{\circ}-125^{\circ}$ with a mean of $114^{\circ}(\mathrm{SD}=5)$ and $95 \%$ confidence interval between $113^{\circ}-115^{\circ}$ for children.

It's well known that cranial features different between races. Therefore, the normal value of the basal angle reported in Western literature may be different from the normal value measured in Eastern populations. The skull appearance has been commonly grouped into 3 major types according to racial ancestry, European (Caucasoid), Asian (Mongoloid) and African (Negroid). Thailand is an Asian country, and whether or not the normal value from Western literature can be accurately applied to our population has not yet been determined. To the best of our knowledge, we cannot find the normal value of basal angle using this modified MR imaging technique in Asians, which includes the Thai population. A published data about the basal angle measured on plain skull film, not by MRI, in Thai population revealed a rather wide range of normal value between $114^{\circ}-151^{\circ}$ (mean $126^{\circ}, \mathrm{SD}=8.1$ ) in male and $109^{\circ}-154^{\circ}$ (mean $129^{\circ}$ and $\mathrm{SD}=6.6$ ) in female [3]. Another study from Japan by Nawata et al. revealed mean basal angle in male $=133^{\circ}(\mathrm{SD}=6.4)$ and in female $=133^{\circ}(\mathrm{SD}=6.6)[4,5]$. Although Thai and Japanese are Asian populations, Thai population revealed slightly smaller mean basal angle compared with Japanese population with statistically difference [3].

The objective of our study was to determine the normal value of basal angle measured using the modified MR imaging technique in Thai population, which may represent Southeast Asia, and to compare with the standard value obtained by Koenigsberg et al. in a Western population.

\section{MATERIALS AND METHODS}

This retrospective study was approved by our Institutional Review Board. The medical records and MRI scans of 200 adults (mean age 57.7 years old; age range 1588 years old) including 90 men and 110 women and 50 children (mean age 7.1 years old; age range 1-14 years old) including 29 boys and 21 girls between January 2013 and May 2015 were included in the study.

Adult patients considered to have a normal skull base angle were randomly selected from the Picture Archive and Communication System (Synapse PACS, Fujifilm version 3.2.0). All patients underwent MR imaging on a 3 Tesla scanner (Achieva, Philips Medical Imaging System, Best, the Netherlands), equipped with an 8-channel head coil with SENSE factor or on a 1.5 Tesla (Ingenia, Phillips, the Netherlands), equipped with a 15-channels head coil. Patients with tumors or clinical conditions that may be related to abnormal basal angle, such as craniofacial anomalies, osteogenesis imperfecta, craniocleidodysostosis, Chiari malformations, Hurler's disease, Paget disease, osteomalacia, rickets, rheumatoid arthritis, neurofibromatosis, infection and trauma of the skull base were excluded from the study.

The modified MR imaging method measured the angles formed by a line extending across the anterior cranial fossa to the tip of the dorsum sellae and another line drawn along the posterior margin of the clivus in mid sagittal SE T1 weighted image (Figure 1) by Reader 1 (a senior radiologic resident) and Reader 2 (a neuroradiologist with 21 years's experience).

The mean values in the adult populations in different age ranges (16-25, 25-60, and $>60$ years old) and in the child population $(\leq 5,6-10$ and $11-15$ years old) were analyzed by the ANOVA test. The mean values in the male and female populations in 
the same age groups were analyzed by two sample t-tests. Inter-observer correlation was evaluated by the Pearson correlation coefficient and Bland-Altman plot. Overall mean values from both observers were determined. Statistical analysis was performed using R program version 3.2.2, R Core Team (2015).

\section{RESULTS}

Mean skull base angle obtained from 200 adults by observer 1 was $114.5^{\circ}$ (range: $100^{\circ}-129^{\circ}, \mathrm{SD}=5.9,95 \% \mathrm{CI}=113.7^{\circ}-115.3^{\circ}$ ) and mean skull base angle obtained from observer 2 was $115.5^{\circ}$ (range: $101^{\circ}-131^{\circ}, \mathrm{SD}=5.9,95 \% \mathrm{CI}=114.7-116.3$ ). The overall mean skull base angle obtained from both observers was $115^{\circ}$ (range: $100.5^{\circ}-130^{\circ}$, $\mathrm{SD}=5.7,95 \% \mathrm{CI}=114.2^{\circ}-115.8^{\circ}$ ). There was good agreement between the 2 observers with a Pearson inter-observer correlation coefficient of 0.85 . Furthermore, good correlation between both observers was demonstrated by the Bland-Altman plot due to the small differences between the two observers at the mean of $2.49^{\circ}, \mathrm{SD}=2.26$ (Figure 2).

There was no significant difference between male and female groups in observer 1 with $P$ value $=0.238$ and in observer 2 with $P$ value $=0.93$. There was also no difference among the three age groups under 26 years old, between 26 and 60 years old, and more than 60 years old in both observers with $P$ value $=0.328$ and $=0.475$ in observer 1 and 2, respectively. Mean skull base angle obtained from 50 children by observer

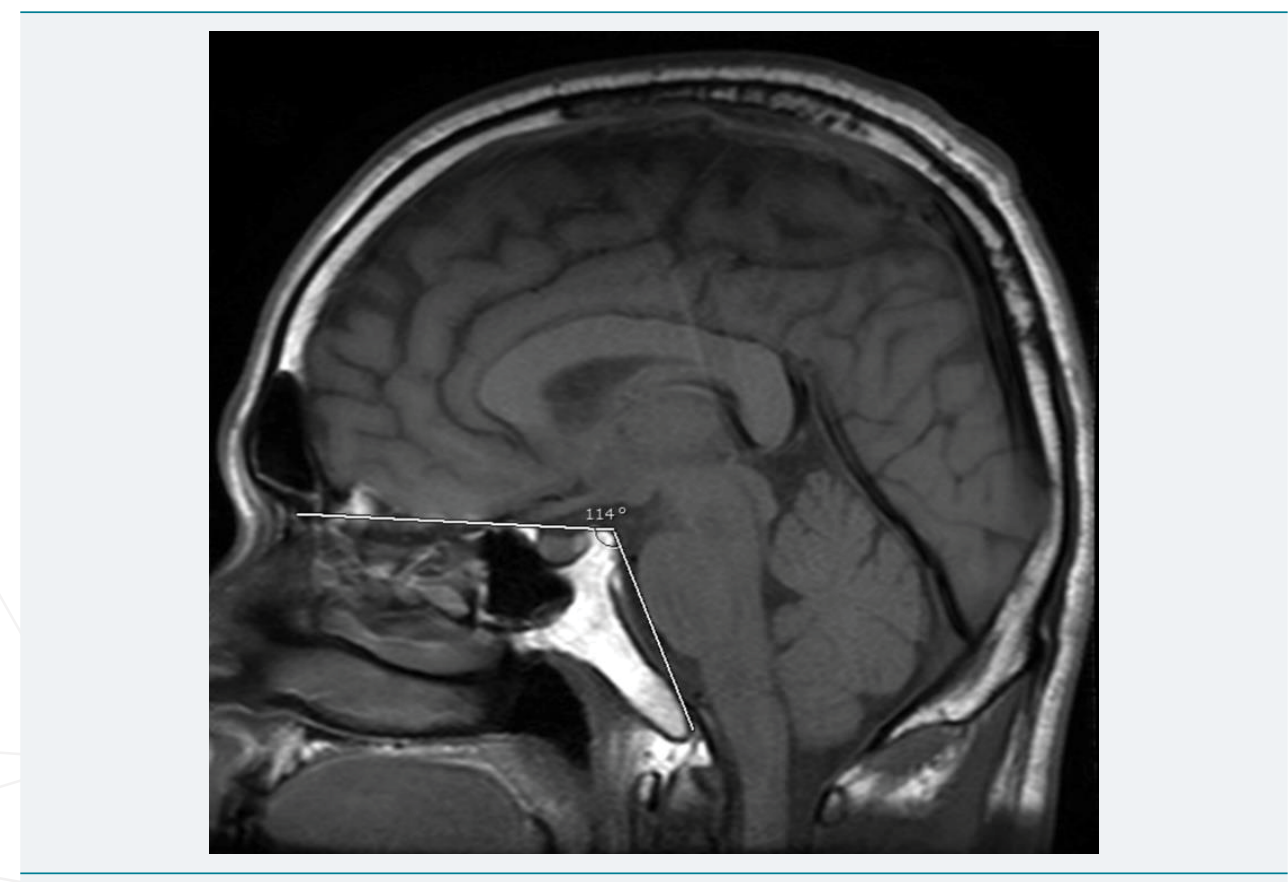

Figure 1: The angle formed by the line extending across the anterior cranial fossa to the tip of the dorsum sellae and another line drawn along the posterior margin of the clivus in mid sagittal SE T1 weighted image.

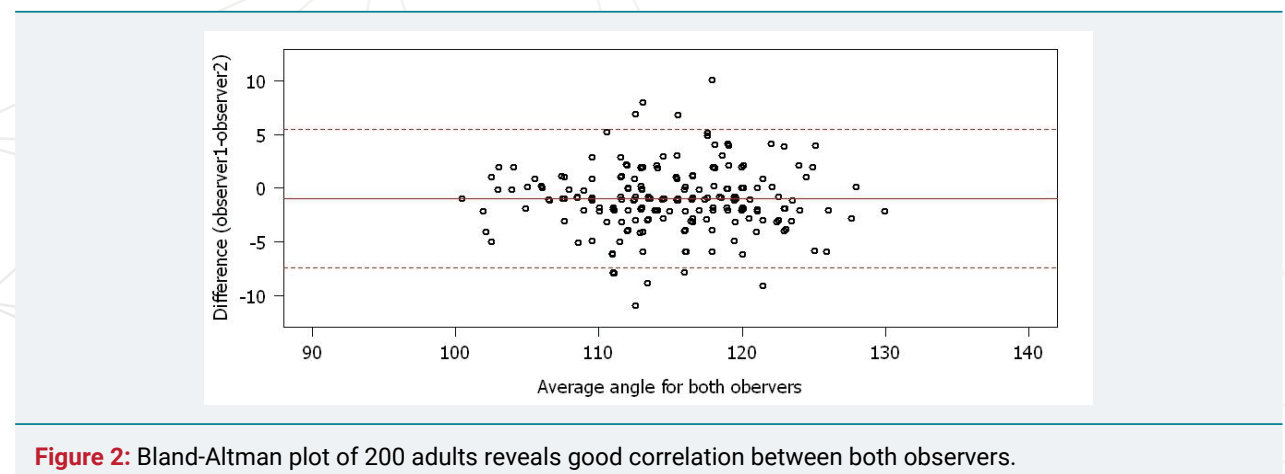

Figure 2: Bland-Altman plot of 200 adults reveals good correlation between both observers. 
1 was $114.3^{\circ}$ (range: $101^{\circ}-131^{\circ}, \mathrm{SD}=7,95 \% \mathrm{CI}=112.4^{\circ}-116.3^{\circ}$ ), and mean skull base angle obtained from observer 2 was $115.1^{\circ}$ (range: $103^{\circ}-130^{\circ}, \mathrm{SD}=6.0,95 \% \mathrm{CI}=113.4$ 116.8). The overall mean skull base angle obtained from both observers was $114.7^{\circ}$ (range: $102^{\circ}-130.5^{\circ}, \mathrm{SD}=6.3,95 \% \mathrm{CI}=112.9^{\circ}-116.5^{\circ}$ ). Good agreement between both observers was demonstrated by the Bland-Altman plot due to the small differences between the two observers at the mean of $2.6^{\circ}, \mathrm{SD}=1.91$ (Figure 3).

There was no significant difference among the three age groups under 6 years old, between 6 to 10 years old and more than 10 years old $(P$ value $=0.401$ in observer 1 and $P$ value $=0.42$ in observer 2 . The mean skull base angle also revealed no significant difference between adult and pediatric groups ( $\mathrm{P}$ value $=0.865$ in observer 1 and 0.681 in observer 2).

\section{DISCUSSION}

Using the modified MR imaging technique, the mean skull base angle of Thai adults $\left(115^{\circ} \mathrm{SD}=5.7,95 \% \mathrm{CI}=114.2^{\circ}-115.8^{\circ}\right)$ was slightly smaller than the mean skull base angle measured from the western population by Koenigsberg et al. [1] $\left(117^{\circ}, \mathrm{SD}=6\right.$, 95\% CI $116^{\circ}-118^{\circ}$ ) (Table 1).

These findings may be explained by the smaller stature of Thai population compared with the Western population.

Koenigsberg suggested that the normal values of the mean skull base angle were between $105^{\circ}-127^{\circ}$ for adults and $104^{\circ}-124^{\circ}$ for children by using the mean skull base angles $\pm 2 \mathrm{SD}$. We also used the similar hypothesis and found basal angle range of $103.6^{\circ}-126.4^{\circ}$ with the real maximum basal angle obtained from observer 2 in our study was $131^{\circ}$. These values may be used as a guide for the potential range of normal skull base angles in Thai population, and possibly also the Southeast Asian population. When measured using the modified MR imaging technique, a basal angle of greater than $131^{\circ}$ may be associated with a diagnosis of platybasia.

Unlike the results from the Western population, no significant differences in the mean skull base angles between adults and children were found in our study. Due to the small number of children in our study, the obtained mean skull base angles in children $\left(114.7^{\circ}, \mathrm{SD}=6.3,95 \% \mathrm{CI}=112.9^{\circ}-116.5^{\circ}\right)$ may not be a good representative value of the children population in Thailand. However, only minimal differences were found

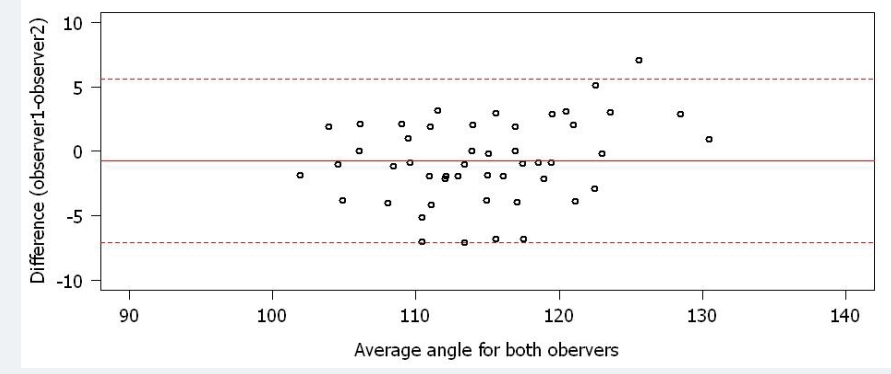

Figure 3: Bland-Altman plot of 50 children reveals good correlation between both observers.

Table 1: Comparison of the mean basal angle using the modified MR imaging technique.

\begin{tabular}{|c|c|c|c|c|}
\hline & Overall Mean & Minimum & Maximum & $95 \% \mathrm{Cl}$ \\
\hline Koenigsberg (Adults) & $117^{\circ}$ & $100^{\circ}$ & $127^{\circ}$ & $116^{\circ}-118^{\circ}$ \\
\hline Koenigsberg (Children) & $114^{\circ}$ & $103^{\circ}$ & $125^{\circ}$ & $113^{\circ}-115^{\circ}$ \\
\hline $\begin{array}{c}\text { Our study } \\
\text { (Adults) }\end{array}$ & $115^{\circ}$ & $100.5^{\circ}$ & $130^{\circ}$ & $114.2^{\circ}-115.8^{\circ}$ \\
\hline Our study* (Children) & $114.7^{\circ}$ & $102^{\circ}$ & $130.5^{\circ}$ & $112.9^{\circ}-116.5^{\circ}$ \\
\hline
\end{tabular}


in mean skull base angle among our child population when compared with a study from the Western $\left(114^{\circ}, \mathrm{SD}=5,95 \% \mathrm{CI}=113^{\circ}-115^{\circ}\right)$. These findings may probably be explained by the rather similar stature of children in all parts of the world.

Platybasia and basilar invagination often appear together [2,6], and they can occur in a variety of congenital craniofacial anomalies, such as osteogenesis imperfecta, craniocleidodysostosis and Arnold-Chiari malformation. They can also occur in acquired disorders, such as Paget disease, osteomalacia, rickets, senile atrophy, hyperparathyroidism, localized bone destruction, and trauma. Clinical manifestations of basilar invagination include signs and symptoms of brainstem and upper cervical cord compression or disturbances of CSF circulation causing hydrocephalus $[1,7]$. When appearing as an isolated finding, platybasia is not clinically important and most patients are asymptomatic [1]. No treatment is indicated unless there is impingement or compression of brain or nerve roots. In some patients, posterior decompression, usually in conjunction with fusion of the skull to the upper cervical spine may be required.

\section{CONCLUSION}

The mean adult skull base angle measured using the modified MR imaging method in Thai population was slightly smaller than in a Western population, while the mean skull base angle of children was quite similar. The normal basal angle ranges in adults of between $103.6^{\circ}-126.4^{\circ}$ may be used as a guide for the potential range of normal skull base angles in the Thai population and possibly also the Southeast Asian population.

\section{REFERENCES}

1. Koenigsberg RA, Vakil N, Hong TA, Htaik T, Faerber E, et al. Evaluation of platybasia with MR imaging. AJNR Am J Neuroradiol. 2005; 26: 89-92. Ref.: https://goo.gl/nqrBmr

2. Burgener FA, Komano M, Pudas T. Differential Diagnosis in Conventional Radiology. $3^{\text {rd }}$ ed. New York: Thieme 2008.

3. Suwanwela N, Suwanwela C. Radiology of skull. Bangkok: Chulalongkorn Press. 1983.

4. Nawata H. [On x-ray craniometry in clinical neurology. II. Studies on statistics and various methods of measurement of 500 normal and 50 abnormal persons]. No To Shinkei. 1963; 15: 467-473. Ref.: https://goo.gl/fyDraf

5. Nawata H. [Roentgencraniometry in clinical neurology. I. Critical study of statics and various methods of measurement in 500 normal persons and 50 normal cases]. No To Shinkei. 1963; 15: 385-398. Ref.: https://goo.gl/ti85NR

6. Bambakidis NC, Dickman CA, Spetzler RF, Sonntag VKH. Surgery of the Craniovertebral Junction. $2^{\text {nd }}$ ed. New York: Thieme. 2013.

7. Farrer RM, Meschan I. Roentgen Signs in Diagnostic Imaging, Spine and Cervical Nervous System. 2nd ed. Philadelphia: WB Saunders; 1985. 